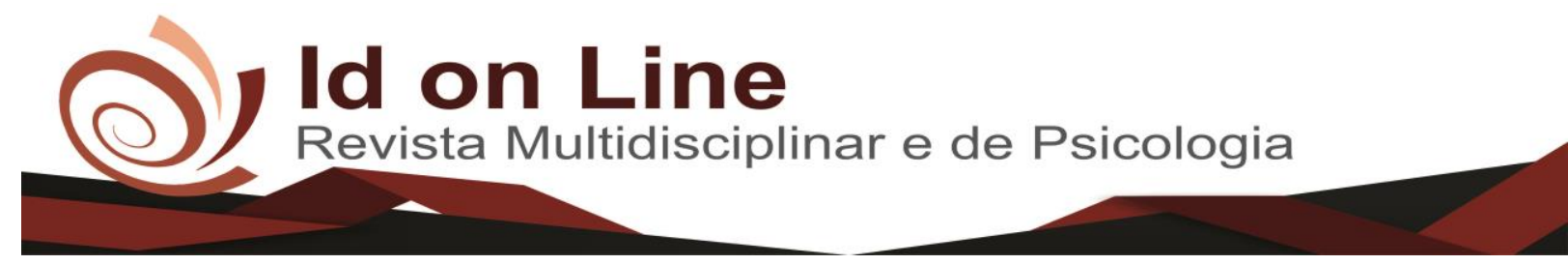

Relato de Caso

\title{
Uso de membrana de polipropileno na instalação de implante dentário: Relato de Caso
}

\author{
Joana Louise Cardoso Viana ${ }^{1}$; Larissa Ledo Pereira Sant'Ana ${ }^{2}$
}

\begin{abstract}
Resumo: O presente estudo relata um caso clínico de um indivíduo que apresentou defeito ósseo na região vestibular do elemento 24,e se submeteu a instalação de implante dentário. No ato da instalação do implante, o defeito ósseo foi coberto com barreira regenerativa de polipropileno, exposta ao meio bucal, com o objetivo de estabilizar o coágulo e formar osso vestibular e tecido mole. A membrana foi retirada após quinze dias de cirurgia. O relato em questão evidencia que no intervalo de tempo analisado, pôde-se notar o aparecimento de tecido ósseo e conjuntivo suficiente para favorecer a estética e a função da região operada. Pode-se perceber que a utilização da técnica de regeneração óssea guiada com o uso de barreira de polipropileno é bastante viável para corrigir defeitos ósseos.
\end{abstract}

Palavras-chave:Regeneração óssea guiada; Membrana de polipropileno; Implante dentário.

\section{Polypropylene Membrane Using the Dental Implant Procedure: A Case Report}

\begin{abstract}
The present study reports a clinical case of an individual who presented a bone defect in the vestibular region of element 24, and underwent dental implant installation. At implant installation, the bone defect was covered with a polypropylene regenerative barrier, exposed to the buccal medium, aiming to stabilize the clot and form buccal bone and soft tissue. The membrane was removed after fifteen days of surgery. The report in question shows that in the time interval analyzed, the appearance of sufficient bone and connective tissue could be observed to favor the aesthetics and function of the operated region. It can be noticed that the use of guided bone regeneration technique with the use of polypropylene barrier is quite feasible to correct bone defects.
\end{abstract}

Keywords: Guided bone regeneration; Polypropylene membrane; Dental implant.

\section{Introdução}

Buscando restabelecer as funções, os implantes osseointegrados apareceram como uma possibilidade de tratamento para pacientes que visam resgatar suas funções em regiões que antes eram edêntulas (GALVAGNI, 2015 ). O implante osseointegrado funciona através de uma conexão direta, funcional e estruturada entre o osso e a superfície do implante.

\footnotetext{
${ }^{1}$ Graduanda em Odontologia da Faculdade Independente do Nordeste - FAINOR, da Conquista, BA, Brasil. Contato: jooana_louise@hotmail.com

${ }^{2}$ Professora do curso de Odontologia da Faculdade Independente do Nordeste - FAINOR, Vitória da Conquista, BA, Brasil. Contato: larissaledo@hotmail.com
} 
O alto nível de biocompatibilidade é alcançado devido ao óxido de titânio presente na superfície do implante (SILVA; SALOMÃO e SIQUEIRA, 2013).

Entretanto, nem sempre é fácil alcançar esse resultado, posto que parte dos pacientes não dispõe de uma porção óssea suficiente para conseguir a colocação dos implantes de forma correta (GALVAGNI, 2015). Ainda que se tente executar uma exodontia com o mínimo dano ao tecido ósseo, fatores como a condição anatômica da unidade dental removida ou técnica cirúrgica utilizada, podem auxiliar no processo de reabsorção óssea alveolar (PIMENTEL, 2010).

O aparecimento de defeitos ósseos alveolares é recorrente de procedimentos de exodontias de um ou mais dentes. É de suma importância que haja a preservação de osso alveolar remanescente, o que tem sido um grande desafio, principalmente quando se trata de uma extensa perda dentária (NESI; OLIVEIRA e MOLINA, 2013). Essas reabsorções, dependendo do nível de ocorrência dificultam ou até impossibilitam a reabilitação, tanto do ponto de vista funcional como também estético (ZAVANELLI RA, 2011). Procurando melhores resultados estético-funcionais, o uso de enxertos ósseos e membranas têm sido bastante empregados. Estes produtos trabalham seguindo o princípio biológico de Regeneração Óssea Guiada (ROG), que se fundamenta na formação de uma zona segregada para a ocupação pelos vasos sanguíneos e células osteoprogenitoras, preservando o reparo ósseo em combate ao desenvolvimento de tecidos não osteogênicos que têm rapidez de crescimento maior que as células osteogênicas (NESI; OLIVEIRA e MOLINA, 2013).

As barreiras para conservação do coágulo no alvéolo já são de uso corrente, uma vez que são utilizadas no auxílio da ROG segurando o coágulo sanguíneo que é um abundante suprimento de plaquetas e fatores de crescimento que ocasionam a regeneração óssea alveolar (SALOMÃO; JUNIOR e FONSECA , 2016; MUNIR e SIQUEIRA, 2010).

Há pouco tempo foi criada uma barreira de polipropileno que, diferente das outras, pode ser exposta ao meio bucal e apresenta-se viável (MUNIR e SIQUEIRA, 2010) 'Suas características como a impermeabilidade, resistência, maleabilidade, passividade ao corte, além de permitir a organização do coágulo, a tornaram ideal para possibilitar alcançar uma ROG eficaz o suficiente para conceder uma reparação (ZEPPINI, 2014). 
Por meio da ROG juntamente com o uso da membrana de Polipropileno Bone Heal ®, tornou-se viável que os cirurgiões dentistas consigam uma neoformação óssea conservando as suas proporções, ou até diminuindo a seriedade de defeitos gerados nos tecidos posteriormente a una exodontias (JUNG RE, 2013).

Sendo assim, o presente trabalho possui como objetivo relatar um caso clínico em que foi instalado um implante dentário simultaneamente a uma membrana de polipropileno, com o objetivo de corrigir um defeito ósseo vestibular na região do elemento 24 , bem como trazer uma revisão de literatura sobre o uso da membrana de Polipropileno Bone Heal em defeito ósseo, ressaltando suas indicações, características, vantagens e técnicas para colocação.

\section{Relato de Caso}

Paciente de 42 anos, sexo feminino, leucoderrna e sem alterações sistêmicas, procurou uma clínica odontológica com queixa principal relacionada à estética dentária. Após exame clínico e exames complementares, foi diagnosticada ausência do elemento 24 (Figura 1) além de grande perda óssea da parede vestibular (Figura 2), que foi confirmada no exame de tomografia computadorizada volumétrica cone beam. Sendo assim, foi indicada a realização da instalação de um implante dentário na região do elemento 24 , com uso simultâneo de uma membrana de polipropileno. Foi realizada uma incisão intrassulcular na região do elemento 24 e um retalho de espessura total foi cuidadosamente feito, a fim de se obter a exposição de todo o defeito ósseo periodontal presente na vestibular. Foi realizado a instalação do implante cone morse (Neodent $\left.{ }^{\circledR}\right)$. 


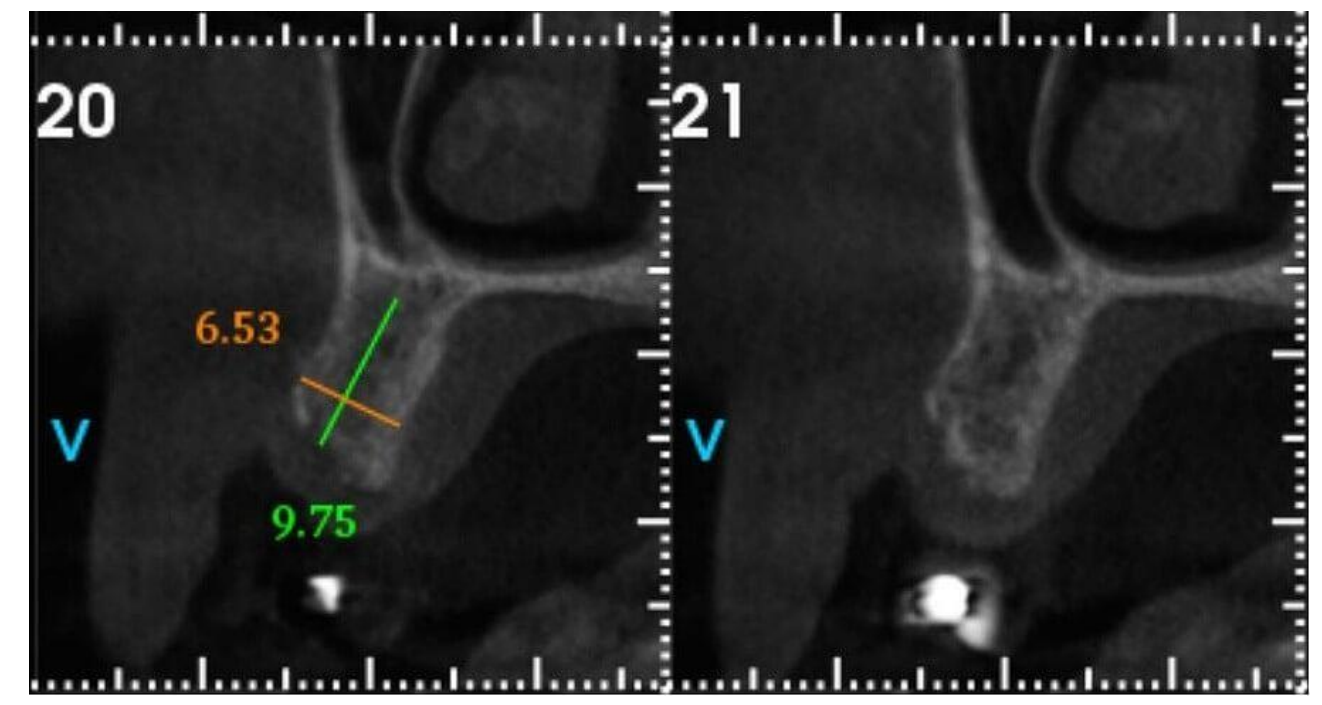

Figura1: Tomografia inicial demonstrando disponibilidade óssea para instalação do implante em posição tridimensional ideal.

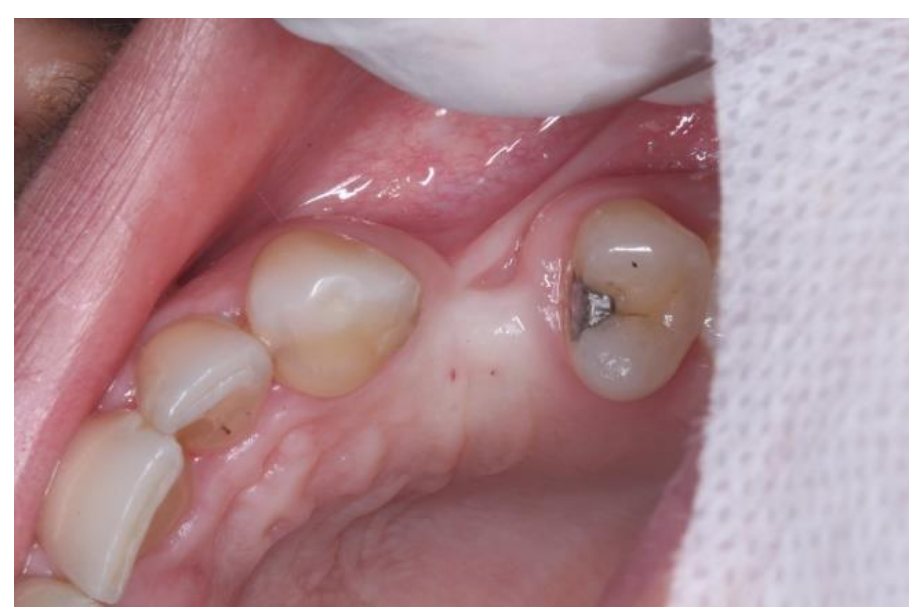

Figura 2a: Aspecto inicial. Nota-se grande perda de volume vestibular.

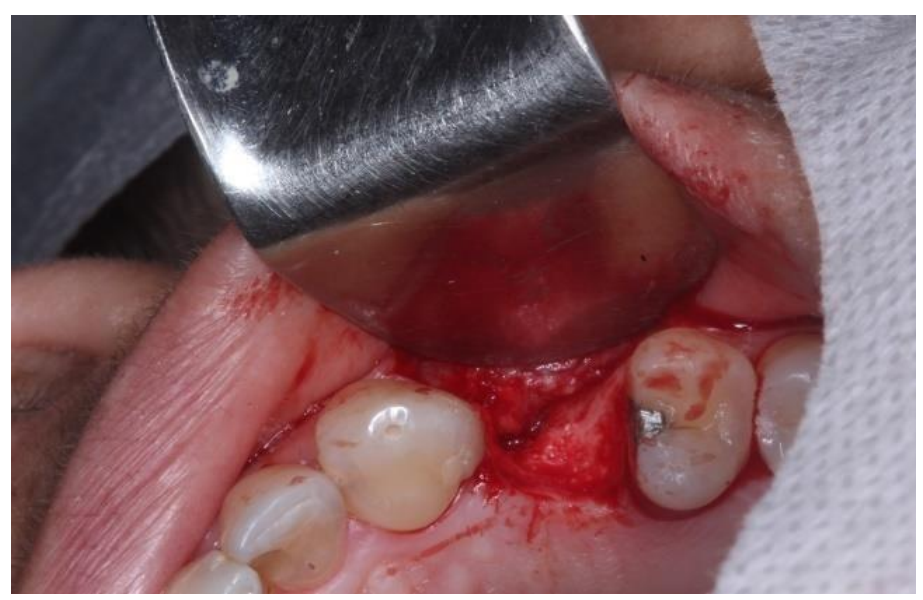

Figura 2b: Volume ósseo após o rebatimento do retalho. 
Foi instalado o implante dentário (Figura 3) no qual se obteve uma estabilidade primária de $35 \mathrm{~N}$ carga. O implante foi posicionado $4 \mathrm{~mm}$ acima da junção amelocementária dos dentes vizinhos. Após instalação do implante, foi indicada regeneração óssea guiada com barreira de polipropileno Bone Heal® (Sistema INP, São Paulo), a fim de manter a arquitetura do rebordo alveolar.

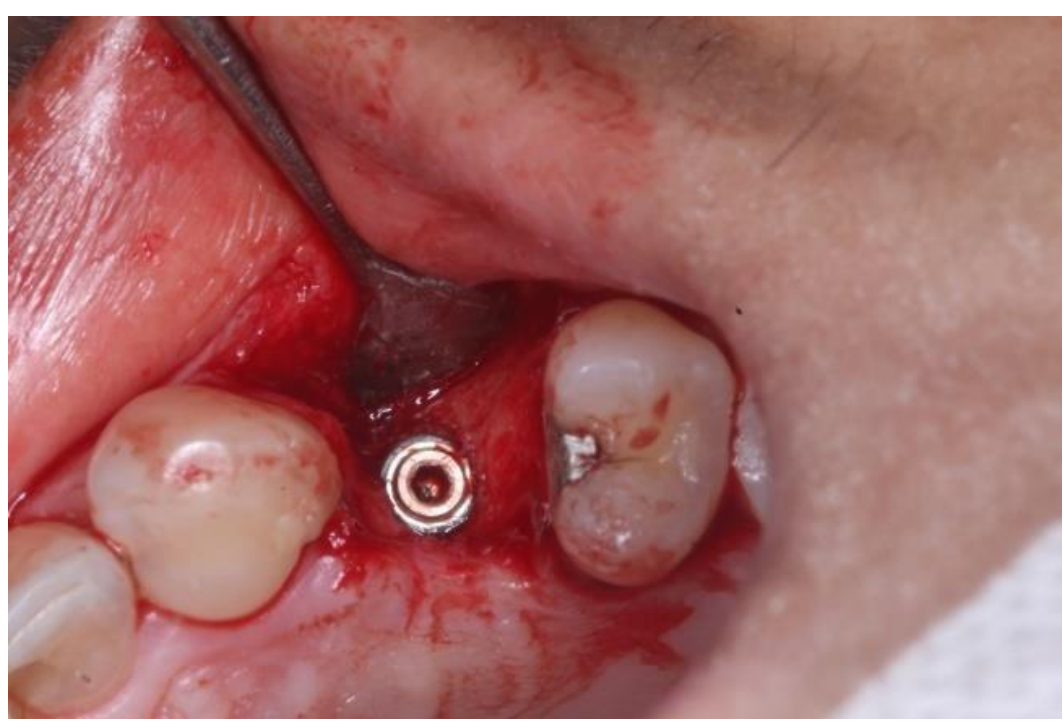

Figura 3: Instalação do implante dentário em posição ideal.

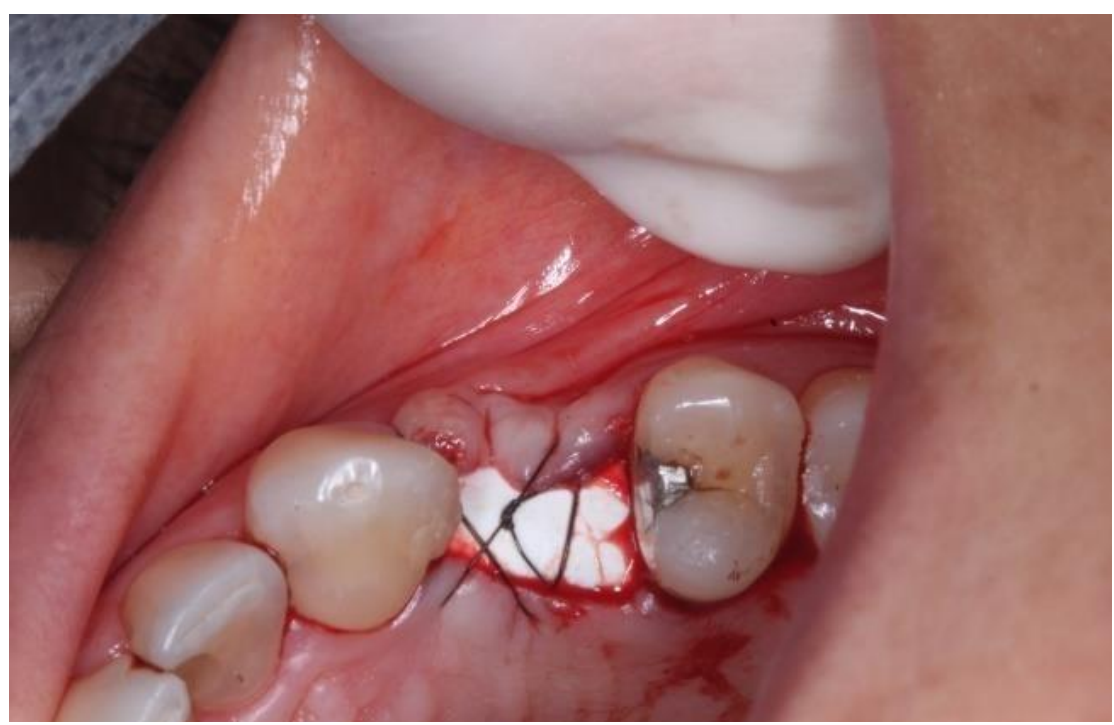

Figura 4: Instalação da membrana de polipropilenoe sutura na mesma sessão da instalação do implante dentário. 
A barreira foi inserida entre os retalhos vestibular e palatino sobre o implante recémcolocado, sendo mantida em posição através de sutura apenas nos retalhos. As margens dos retalhos foram deixadas distantes entre si, de tal modo que a barreira permaneceu intencionalmente exposta ao meio bucal (Figura 4). Após 15 dias, foi removida a membrana e o\$ pontos. A figura 5 mostra o aspecto clinicamente saudável dos tecidos no pós-operatório após 6 meses, foi constatada a osseointegração, bem como grande ganho tecidual vestibular (Figura 6 e 7).
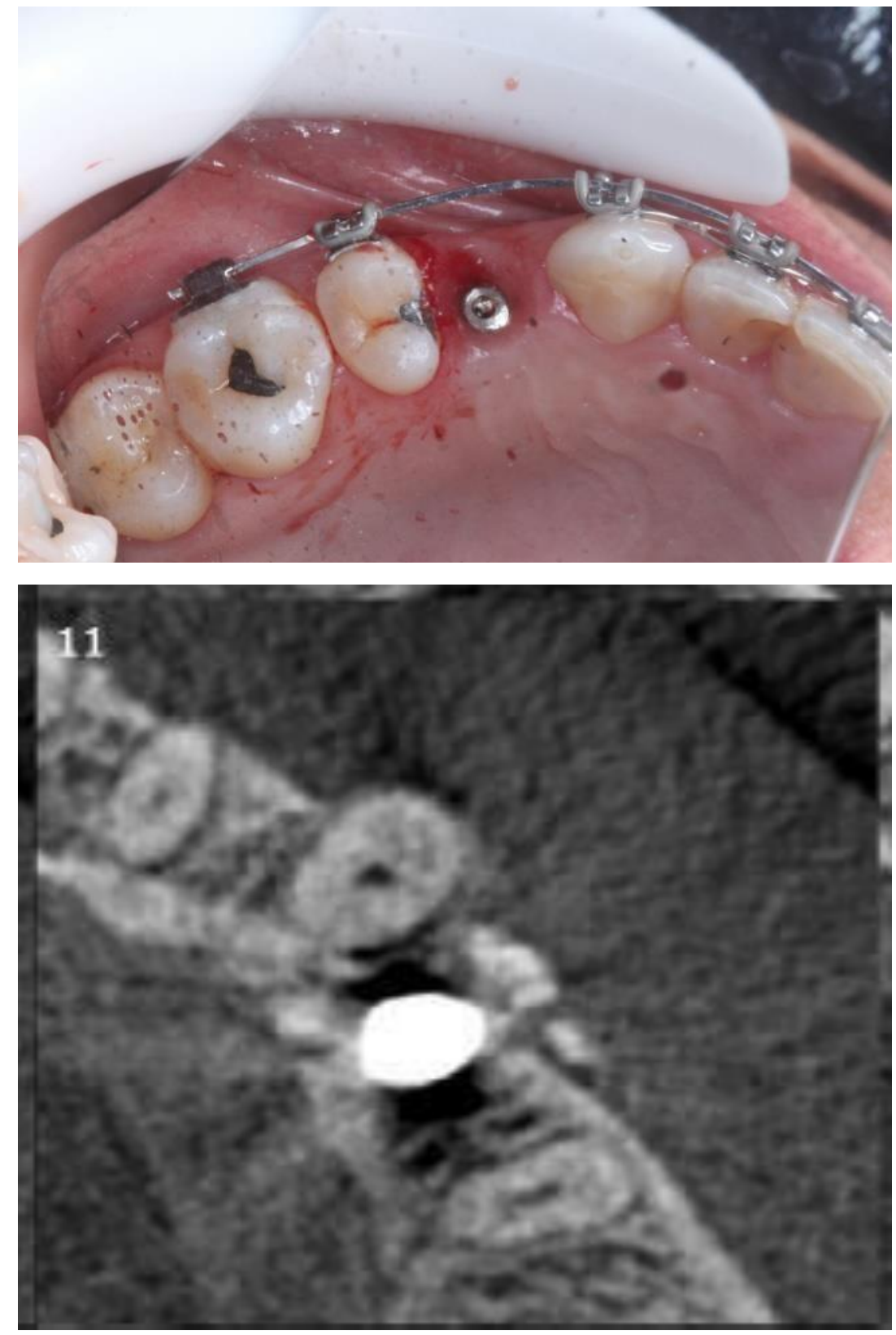

Figura 5a: Reabertura após 6 meses. Nota-se um ganho considerável de volume vestibular.

Figura 6: Imagem tomográfica final após 6 meses da instalação do implante mostrando a formação de tecido ósseo na parede vestibular. 


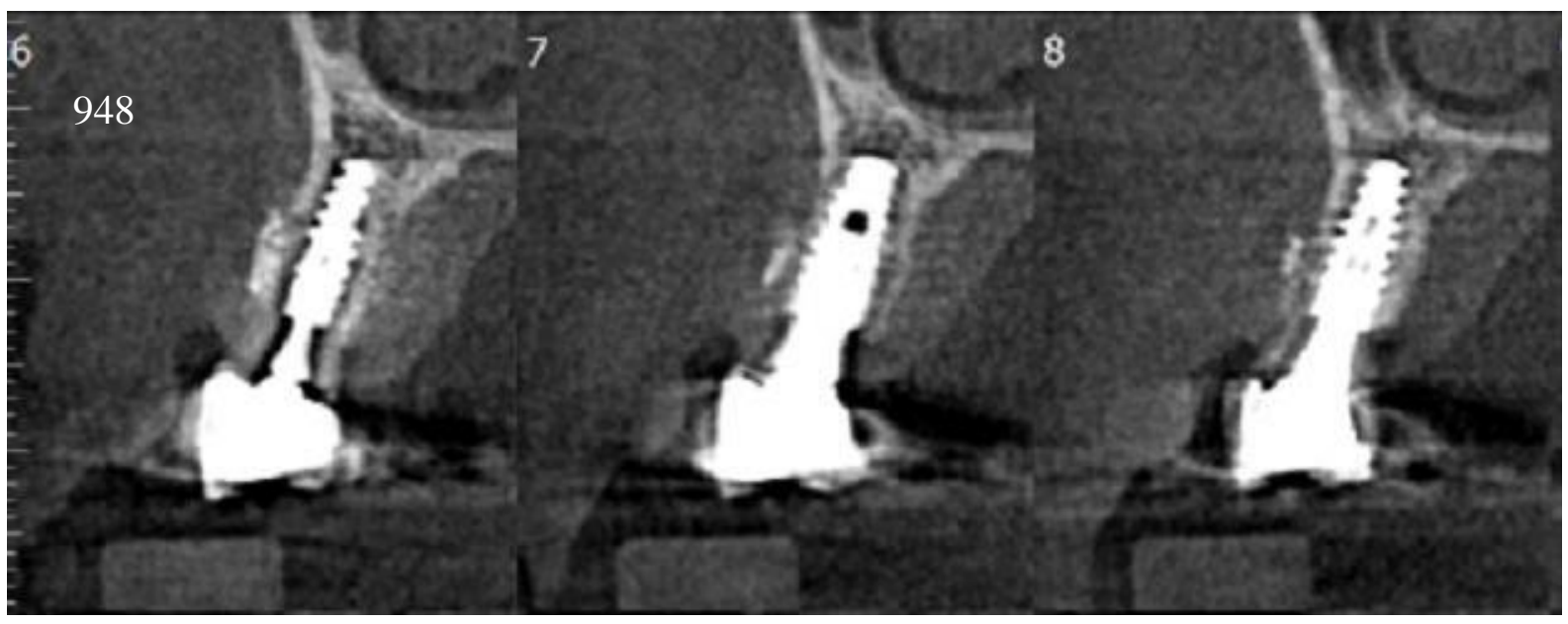

Figura 7: Implante ósseointegrado e neoformação óssea na base do implante.

\section{Discussão}

A permutação de um elemento dentário pelos implantes osseointegrados constitui uma possibilidade significativa na reabilitação estética e functional (OLIVEIRA, et al., 2008). O protocolo clássico descrito pela primeira vez por Branemark em 1981(PRIMO, et al., 2011) sugere a inserção dos implantes somente após a cicatrização óssea completa da região receptora, normalmente e após 6 meses (BRÅNEMARK, et al., 1969).

$\mathrm{Na}$ implantodontia moderna, é concebível que um tratamento seja realizado em curto período e com menor quantidade de intervenções cirúrgicas, o que colabora diretamente para a aprovação do paciente. No caso em questão, a instalação do implante ocorreu concomitantemente a colocação da barreira, diminuindo a quantidade de intervenções. Os protocolos e diretrizes tradicionais sugerem esperar um intervalo de dois a três meses para remodelação óssea após a extração do dente objetivando em sequência a colocação do implante e um período adicional de três a seis meses sem cargas oclusais favorecendo a cicatrização, que é imprescindível para osseointegração (ADELL, et al., 1981; OLIVEIRA FILHO, et al., 2015; PELLIZZER, 2013). 
Uma das limitações que ocorrem na implantodontia se relaciona à perda óssea marginal crônica média de $0,9 \mathrm{~mm}$ no primeiro ano e $0,1 \mathrm{~mm}$ em cada ano consecutivo no tecido em volta do implante (GOODACRE, et al.2003; BUENO, et al., 2016). Esse acontecimento pode

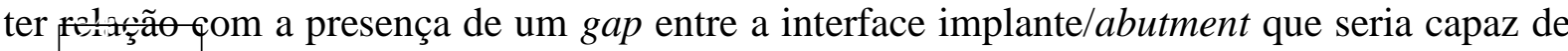
conceher uma inflamação local além de um acúmulo de tensões na área cervical do implante, resultado das cargas mastigatórias (MARTINS, et al., 2017; DE LIMA JÚNIOR, et al., 2017).A escassez de osso nos rebordos alveolares tem gerado um vasto problema na reabilitação estético-funcional em pacientes que tenham sido alvo de traumatismos dentoalveolares, extrações dentárias traumáticas, ausência dentária congênita, patologias que envolvam maxila e mandíbula, além de infecções. A perda de tecido ósseo pode se dar também por doença periodontal, cirurgias traumáticas, ou até mesmo por motivos fisiológicos gerados pela falta de função do rebordo ou carga protética imprópria(ALVES, et al., 2014). Muitos dos pacientes, que têm indicação para reabilitação com implantes dentários, deverão passar por procedimentos reconstrutivos da estrutura óssea, visando viabilizar a instalação correta dos implantes (LOUROPOULOU; SLOT DE e VAN DER WEIJDEN, 2015; NESI; DE OLIVEIRA e MOLINA GO, 2014).

Manter a arquitetura do osso alveolar durante o reparo após a extração dentária é um desafio a ser vencido. O meio de reparação alveolar está associado a uma remodelação tecidual que resulta em grande perda de volume ósseo. A reabsorção e o remodelamento do rebordo alveolar, após a remoção do dente, é um fenômeno natural da cicatrização, fisiologicamente indesejável e possivelmente inevitável que pode prejudicar a colocação do implante. Esta situação é particularmente importante na região anterior da maxila, na qual a posição proeminente da raiz é geralmente acompanhada por uma parede vestibular extremamente fina e frágil, que pode ser danificada durante a extração dentária (BARRETO, et al 2018).

Como alternativa de resolução da ausência de tecido ósseo, diversos biomateriais surgiram com o intuito principal de reduzir os defeitos ósseos, gerando uma melhora estética. A Regeneração Óssea Guiada (ROG) pode ser definida como um procedimento cirúrgico na qual são utilizados materiais enxertados e membranas como barreira a fim de incentivar e indicar o crescimento de novo osso em defeitos pré-existentes (BARGES, 2018). 
Uma das características recomendadas para o emprego da técnica de ROG é que as barreiras controlam ou evitam o infiltrado de células de tecidos moles, contribuindo para a proliferação de células ósseas dentro do alvéolo ósseo. O coágulo sanguíneo é indispensável para a cicatrização do rebordo alveolar, visto que contém os elementos fundamentais ao processo de regeneração óssea. Sendo assim, o objetivo da barreira é conter o coágulo em determinada região (KASAYA, 2017).

O uso de barreiras que possibilitam sua exposição no meio bucal é interessante, pois excluem a necessidade de realizar incisões e retalhos maiores para alcançar o fechamento primário, contrariando as membranas reabsorvíveis que necessitam de grandes incisões, tornando o procedimento muito mais invasivo além de exigir uma maior habilidade técnica e ainda expõe maior risco ao paciente (SALOMÃO e SIQUEIRA, 2010a).

No caso em questão, a barreira impermeável empregada, foi mantida em posição sem passar poralterações na forma, possibilitando a retenção do coágulo para a formação do tecido ósseo, colaborando para manutençãoda forma e as dimensões do rebordo alveolar. Essa membrana de polipropileno já tem seu uso bastante frequente na medicina por ser considerado biocompatível; sua utilização na cavidade oral auxilia na retençãodo coágulo sanguíneo, isolando-o do meio bucal e contribui para a regeneração do rebordo alveolar (SALOMÃO e SIQUEIRA, 2010b).

Durante o processo de reparação tecidual, as membranas atuam na prevenção da migração e ação dos fibroblastos e eliminam elementos inibidores por desencadearem uma vascularização adequada, estabilização, espaço para aumento ósseo e exclusão de tecidos competidores. Ainda, auxiliam a concentrar fatores estimuladores de crescimento local, sendo assim fonte de células osteogênicas (PEREIRA, et al., 2016). Foi possível notar através do exame tomográfico que além de tecido conjuntivo, houve uma formação considerável de tecido ósseo, comprovando a eficácia na utilização da membrana.

No caso apresentado, a utilização da barreira de polipropileno (Bone Heal@, São Paulo) não apresentou efeitos inflamatórios durante sua presença na cavidade bucal conforme as condições clínicas avaliadas no paciente. A barreira de polipropileno (Bone Heal®, São Paulo), propositadamente exposta na cavidade bucal, sustentou-se na posição instalada, favorecendo para o processo de formação de tecido ósseo. Sua remoção após quinze dias de 
proservação é visivelmente viável para a manutenção do coágulo e contribui na redução de procedimentos cirúrgicos mais traumáticos e invasivos (PEREIRA, et al., 2016).

É importante destacar a importância de estudosprospectivos longitudinais para observar o comportamento do rebordo alveolar regenerado com essa técnica, todavia o uso deste tipo de membrana é extremamente promissor em ROG e, inicialmente, confronta conceitos rígidos da implantodontia, como da necessidade de enxertos para recuperar defeitos ósseos ou de que não se pode deixar a barreira exposta no meio bucal, pois contaminaria o coágulo, como se os coágulos de milhões de dentes extraídos até a presente data não ficassem em contato com o meio bucal. Talvez seja uma mudança de padrão que ainda assusta, mas que é desafiador e pode ser altamente benéfico aos pacientes (SALOMÃO e SIQUEIRA, 2010c; SALOMÃO; SIQUEIRA e ALVAREZ, 2010a; SALOMÃO; SIQUEIRA e ALVAREZ, 2010b).

\section{Conclusão}

No caso clínico em questão, o uso da membrana de polipropileno exposta ao meio bucal corroborou para a manutenção do rebordo alveolar acompanhado longitudinalmente.Houve o crescimento não só de tecido conjuntivo, como também de tecido ósseo. A facilidade de acesso e manipulação e o controle participativo nafisiologia tecidual pelo cirurgião dentista faz com que este método seja uma alternativa capaz de auxiliar na minimizaçãoda reabsorção óssea ou mesmo na imobilização do coágulo.Esse tipo de barreira é um importante meio de grande auxíliona prática clínica odontológica.

\section{Referências}

ADELLR, LEKHOLM U, ROCKLERB,BRÅNEMARK, PI. A 15-year study of osseointegrated implants in the treatment of the edentulous jaw. Int. j. oral surg. v.10, n.6, p. 387-16,1981. 
ALVES RTC, et al. Enxertos ósseos autógenos intrabucais em implantodontia: estudo retrospectivo. Rev. cir. traumatol. buco-maxilo-fac. v.14, n.4, p. 9-16, 2014.

BARRETO BR, DE ANDRADE ACRR, DINIZ BB, DE BRITO LGC, DE ABREU CAROLINO R, TEIXEIRA FG. Enxerto ósseo para implante dentário em região anterior de maxila. Arch Health Invest,v. 7, n.1, p.24, 2018.

BORGES, MF. Desenvolvimento de membranas de acetato de celulose incorporadas com aditivos funcionais para tratamentos regenerativos periodontais - Uberlândia. 2018, 94 f. Dissertação (Mestrado em Química) - Universidade Federal de Uberlândia, Uberlândia, 2018.

BRÅNEMARK PI, et al. Intra-osseous anchorage of dental prostheses: I. Experimental studies. Scand. j. plast. reconstr. surg. hand surg. v.3, n.2, p. 81-100, 1969.

BUENO TL, et al. Análise das tensões em diferentes conexões de implante/ abutment. Rev. cir. traumatol. buco-maxilo-fac. v.16, n.1, p.7-12, 2016.

CARVALHO NB, et al. Planejamento em implantodontia: uma visão contemporânea. Rev Cir Traumatol Buco-Maxilo-Fac. v.6, n.4, p.17-2, 2006.

DE LIMA JÚNIOR JL, et al.. Implante mediato após trauma de avulsão dentária associado com enxerto ósseo e gengival: relato de caso. Rev. odontol. Univ. Cid. São Paulo (Online). v.29, n.1, p. 75-80, 2017.

GALVAGNI AM, et al. . Use of non-reabsorbable membrane associated with surgical technique to increase attached gingiva. J. Surg. Clin. Dent. v.4, n.1, p. 8-13, 2015

GOODACRE CJ, et al.. Clinical complications with implants and implant prostheses. The Journal of prosthetic dentistry. v.90, n.2, p.121- 132, 2003.

JUNG RE, et al . Long-term outcome of implantsplaced with guided bone regeneration (GBR) using resorbable and non- resorbablemembranes after 12-14 years, Clin. Oral. Impl. Res.v.24, n.10, p.1065-73, 2013.

KASAYA, MVS. Coágulo, fibrina rica em plaqueta (PRF) ou Bio- OSS em alvéolos frescos: o que utilizar para manutenção aveolar?. 2017. 49 f. Dissertação (Mestrado em Biologia Oral Área de Concentração: Cirurgia e Traumatologia Bucomaxilofacial) - Universidade do Sagrado Coração, Bauru, 2017.

LOUROPOULOU A, Slot DE, Van der Weijden F. Influence of mechanical instruments on the biocompatibility of titanium dental implants surfaces: a systematic review. Clin. oral implants res. v.26, n.7, p. 841-50, 2015.

MARTINS MM, et al. Inter-relação das plataformas dos implantes dentários com a doença Peri-Implantar. Conversas Interdisciplinares. v.13, n.3, p.1-10, 2017. 
MUNIR S, SIQUEIRA JTT. Regeneração óssea guiada através de barreira exposta ao meio bucal após exodontias: relato de caso. Rev. Bras. Implant. v.16, n.3, p.5-7, 2010.

NESI H, DE OLIVEIRA MT, MOLINA GO. Avaliação do uso de membranas na infiltração de tecido conjuntivo em alvéolos de dentes recém-extraídos.Rev. bras. odontol. v.70, n.2, p.13641. 2014.

NESI H, OLIVEIRA MT, MOLINA GO. Avaliação do uso de membranas na infiltração de tecido conjuntivo em alvéolos de dentes recém-extraídos. Rev. bras. odontol. v.70, n.2, p.13641. 2013.

OLIVEIRA A, SOUZA J, THOMÉ G, MELO AC, Sartori I. Implante imediato unitário em função imediata -relato de caso. RFO-UPF. v.13, n.1, p.70-4, 2008.

OLIVEIRA FILHO FDA, et al. Regeneração óssea guiada com carga imediata em zona estética: relato de caso clínico. Rev. cir. traumatol. buco-maxilo-fac. v.15, n.2, p. 33-8, 2015.

PELLIZZER EP, et al. Implantes curtos do tipo cone-Morse: Proporção coroaimplante. Rev. cir. traumatol. buco-maxilo-fac. v.13, n.3, p. 79-86, 2013.

PEREIRA SP, OLIVEIRA JR NG, VIEIRA FD, RODRIGUES CRT, VIEIRA AF, ELIAS WC. Regeneração óssea guiada (rgo) com uso de membrana não reabsorvível de polipropileno-bone heal em alvéolo pós-exodontia - relato de caso. Full Dent. Sci.; v.7, n. 28, p.42-8, 2016.

PIMENTEL GHD, et al. Perda óssea peri-implantar e diferentes sistemas de implantes. Innov. implant. j., biomater. esthet. v. 5, n.2, p.75-1, 2010.

PRIMO BT, et al. Implante imediato para substituição de elemento dentário com fratura radicular: relato de caso clínico. Stomatos.v.17, n.32, p.65-1, 2011.

SILVA BCR, SALOMÃO M, SIQUEIRA JTT. Regeneração de defeito ósseo extenso pósexodontia para instalação de implante osteointegrável com uso de barreira intencionalmente exposta ao meio bucal. Relato de caso clínico. Rev Catarinimplant. v.13, n.15.,p.54-7, 2013.

SALOMÃO M, JUNIOR POT, FONSECA MB. Caso clínico - Regeneração óssea guiada utilizando barreira de polipropileno (Bone Healß), associado a enxerto xenógeno (BIO-OSS $®$ ) e enxerto de tecido conjuntivo, otimizando a reabilitação com implante dental. Rev Catarinense Impl v.18, n.17, p.42-4, 2016.

SALOMÃO M, SIQUEIRA JTT, ALVAREZ FK. Mudança de paradigma na Regeneração Óssea Guiada. Essencial em revista. v.8, n.38, 2010.

SALOMÃO M, SIQUEIRA JTT. Recuperação do rebordo alveolar através de barreira exposta ao meio bucal. Novo paradigma? Rev. Catarin. Implant.; v.10, n.12, p.26-8, 2010. 
SALOMÃO M., SIQUEIRA J.T.T., ALVAREZ F.K. Regeneração óssea guiada em defeitos extensos pós exodontias utilizando membrana exposta ao meio bucal. RevistaImplantNews. v.7, n.6, p.753-9, 2010.

SALOMÃO M, SIQUEIRA JTT. Regeneração óssea guiada através de barreira exposta ao meio bucal após exodontias. Relato de caso. Rev. Brás. Implant. p. 5-7, 2010.

SALOMÃO M, SIQUEIRA JTT. Uso de barreira exposta ao meio bucal para regeneração óssea guiada após a exodontia. Rev. Assoc. Paul. Cir. Dent. v. 64, n.3, p.184-8, 2010.

SALOMÃO M., SIQUEIRA J.T.T. Uso de barreira de polipropileno pós exodontia. Relato de três casos clínicos. Rev. Brás. Implant. p.12-5, 2009.

ZEPPINI LAS. Barreira de polipropileno-Uma nova abordagem para regeneração óssea guiada (ROG). Rev Odontol. (ATO). v.14, n.5, p. 301-7, 2014.

ZAVANELLI RA, et al. Fatores locais e sistêmicos relacionados aos pacientes que podem afetar a osseointegração. RGO. Rev Gaúch. Odontol. v.59, n.1, p.133-46, 2011.

\section{Como citar este artigo (Formato ABNT):}

VIANA, Joana Louise Cardoso; SANT'ANA, Larissa Ledo Pereira. Uso de membrana de polipropileno na instalação. de implante dentário: Relato de Caso. Id on Line Rev.Mult. Psic., 2018, vol.12, n.42, p. 943-955. ISSN: 1981-1179.

Recebido: 20/10/2018;

Aceito: $24 / 10 / 2018$ 